\title{
Comparative Evaluation of Topical Lignocaine Versus Intravenous Lignocaine for Laryngeal Mask Airway Insertion in Wardha, Maharashtra
}

\author{
G. Swathi Reddy ${ }^{1}$, Karuna Taksande ${ }^{2}$ \\ ${ }^{1,2}$ Department of Anaesthesia, Jawaharlal Nehru Medical College, Datta Meghe Institute of Medical Sciences \\ (Deemed To Be University), Sawangi Meghe, Wardha, Maharashtra, India.
}

\section{ABSTRACT}

\section{BACKGROUND}

The purpose of present study was to compare and evaluate both topical lignocaine and intravenous lignocaine for laryngeal mask airway (LMA) insertion prior to propofol. Main objective was to study the conditions for LMA insertion with respect to gagging, coughing, Laryngospasm and No. of attempts for LMA insertion and also study the hemodynamic parameters in both the groups (Heart rate, SBP,DBP, MAP, Sp02)

\section{METHODS}

This study included 60 patients of 30 in each group, ASA I \& II day care surgeries were performed in our hospital between 2019 and 2021. Patients were randomized into two groups. Group I received intravenous lignocaine $1.5 \mathrm{mg} / \mathrm{kg}$ over 30 seconds and group II received topical lignocaine $40 \mathrm{mg}$. Conditions of LMA insertion, gagging, laryngospasm, coughing were noted at the time of insertion, ECG, NIBP, SPO2 and ETCO2 were recorded according to scheduled times.

\section{RESULTS}

In conditions of LMA insertion, difference between both the groups was found to be significant, $\mathrm{P}<0.05$ in groups with first minute rise in heart rate, fall in Systolic blood pressure, diastolic blood pressure, mean arterial pressure was significant. At two minutes and three minutes after the LMA insertion, HR, SBP, DBP, MAP all these parameters changed slightly but these changes were statistically not significant.

\section{CONCLUSIONS}

Prior to Propofol induction, compared to intravenous lignocaine, topical lignocaine $10 \%$ aerosol provided excellent conditions for the insertion of LMA without the use of neuromuscular blockers.

\section{KEY WORDS}

IV Lignocaine, Topical Lignocaine, LMA
Corresponding Author: Dr. G. Swathi Reddy, Junior Resident, Department of Anaesthesia, Jawaharlal Nehru Medical College, Datta Meghe Institute of Medical Sciences (Deemed To Be University), Sawangi Meghe, Wardha, Maharashtra - 442004, India. E-mail: swathireddyg17@gmail.com

DOI: $10.14260 / \mathrm{jemds} / 2021 / 425$

How to Cite This Article:

Reddy GS, Taksande K. Comparative evaluation of topical lignocaine versus intravenous lignocaine for laryngeal mask airway insertion in Wardha, Maharashtra.J Evolution Med Dent Sci 2021;10(28):20782082, DOI: $10.14260 /$ jemds/2021/425

Submission 27-02-2021, Peer Review 11-05-2021, Acceptance 18-05-2021, Published 12-07-2021.

Copyright (C) 2021 G. Swathi Reddy et al. This is an open access article distributed under Creative Commons Attribution License [Attribution 4.0 International (CC BY 4.0)] 


\section{BACKGROUND}

The laryngeal mask airway (LMA) was described in 1983 by Archie Brain. For researchers LMA insertion conditions became prime interest since the time of it's inception. Different types of LMA and insertion techniques have been developed. ${ }^{1}$ A wide variety of medications have been used to improve the insertion conditions of laryngeal mask airway as in general anaesthesia airway morbidity has remained a vital concern.

The most notable recent development in the control of airway is undoubtedly the laryngeal mask airway. It is a relatively new non-invasive ventilatory system designed to be inserted into the hypopharynx without a laryngoscope, which has made a dramatic shift in the management of modern general anaesthesia. LMA insertion prevents overt laryngoscopy, larynx instrumentation and visualisation of the vocal cord. The positioning of the LMA is therefore less stimulating and results in less pressure response than direct laryngoscopy. ${ }^{2}$ In daycare surgeries the techniques of anesthesia should be adapted so as to allow quick patient recovery and minimal side-effects. Overall complications are reduced in surgical patients undergoing general anaesthesia with LMA.

Studies were conducted to find out the various techniques to attenuate the pressor response to laryngoscopy, endotracheal intubation, bronchoscopy, bronchography and extubation. Insertion of LMA requires the airway reflexes to be obtained by general / topical anaesthesia or muscle relaxants. Gagging, coughing or laryngospasm can be caused by intact airway reflexes. When general anaesthesia is used to insert an LMA the depth needed is almost equal or greater than that is required for the insertion of an oropharyngeal airway. ${ }^{3}$

Propofol continues to be the most common induction agent for LMA insertion in doses of $2-2.5 \mathrm{mg} / \mathrm{kg}$ as it suppresses oropharyngeal reflexes, cough reflex, and minimizes the sensitivity of upper airway. However studies stated that the use of propofol alone has a lower success rate for LMA insertion. Many other co induction agents have been used to increase the success rates. Compounds such as midazolam, lignocaine, fentanyl and succinylcholine have been used as co-induction agents to promote insertion of LMA. ${ }^{4-6}$ It was reported from previous studies that when propofol was used in combination with IV Lignocaine it showed coughing (20\%), gagging (56\%) and laryngeal spasm (13\%) during LMA insertion.

Lignocaine was studied previously with thiopentone by giving through intravenous route and topical routes of administration. ${ }^{7}$ Topical lignocaine provided better LMA insertion conditions (86\%) than intravenous lignocaine (63 $\%)$ when used with thiopentone. ${ }^{8}$ Intravenous lignocaine can be effective for decreasing airway sensitivity (55\%) to instrumentation by depressing airway reflexes and decreasing calcium flux in airway smooth muscles. ${ }^{9}$ Intravenous and topical lignocaine have been used with variable success (40\%) to blunt hemodynamic responses to tracheal intubation and extubation. ${ }^{10,11}$

According to previous studies when thiopentone and topical lignocaine spray were used in combination the results were found to be the same as with propofol and IV lignocaine.

We hypothesized that topical lignocaine with propofol induction provided acceptable LMA insertion conditions than intravenous lignocaine with propofol in patients undergoing elective surgery under general anaesthesia.

\section{Objectives}

- To compare the efficacy and safety of topical lignocaine versus intravenous lignocaine prior to propofol for insertion of laryngeal mask airway.

- To study the conditions for LMA insertion with respect to gagging, coughing, laryngospasm and No. of attempts for LMA insertion.

- To study the Haemodynamic parameters in both the groups (Heart rate, SBP, DBP, MAP, SpO2)

\section{METHODS}

The study was carried out after approval by the Jawaharlal Nehru Medical College's Ethics and Screening Committee, DMIMS (DU), in Acharya Vinoba Bhave Rural Hospital (AVBRH), Datta Meghe Institute of Medical Sciences, Sawangi (M), Wardha. It is a comparative experimental prospective study conducted from February 2019 to January 2021

Written and informed consents were obtained from all the patients prior to the procedure. Study was done on patients of American Society of anesthesiology class I and II of both sexes aged in the group of 18 - 50 years.

Patients with refusal to participate in the study, anticipated difficult airway, preoperative comorbidities, pregnant women, risk of gastric content aspiration, any abnormal coagulopathies and known allergy to the drugs given were excluded from the study. With regular studies for urine, haemoglobin percent, TLC, blood urea, blood sugar and serum electrolytes, both group patients underwent a thorough preanesthetic checkup. Baseline chest X - rays and ECG were performed. Basic monitors were applied after moving the patient to the operation theatre, IV line taken and basic parameters were recorded.

Patients were randomly allocated into two groups of equal size. Randomization was done using simple sealed envelope technique prior to study initiation and opened prior to anaesthesia by the investigator who was giving topical or intravenous lignocaine. The study was conducted on 60 adult patients of both sexes undergoing general surgery meeting the inclusion criteria ASA I \& II (no or mild systemic disease over 18 years) were divided into two groups, group I (intravenous lignocaine group) and group II (topical lignocaine group) each with 30 patients on the basis of LMA insertion conditions. All the patients had patent intravenous cannula and standard monitors (noninvasive blood pressure, pulse oximeter and ECG) before starting. A baseline heart rate and blood pressure were recorded after stabilisation for 5 minutes. Group I received intravenous lignocaine $1.5 \mathrm{mg} / \mathrm{kg}$ followed by preoxygenation for three minutes. Group II received $5 \mathrm{ml}$ of $4 \%$ lignocaine spray to the posterior pharynx in sitting position after depressing the tongue with a tongue depressor. The patients were turned supine immediately followed by preoxygenation for 3 minutes. After 3 minutes pre-oxygenation in both groups, intravenous $2 \mathrm{mg} / \mathrm{kg}$ propofol over 15 seconds were injected. 


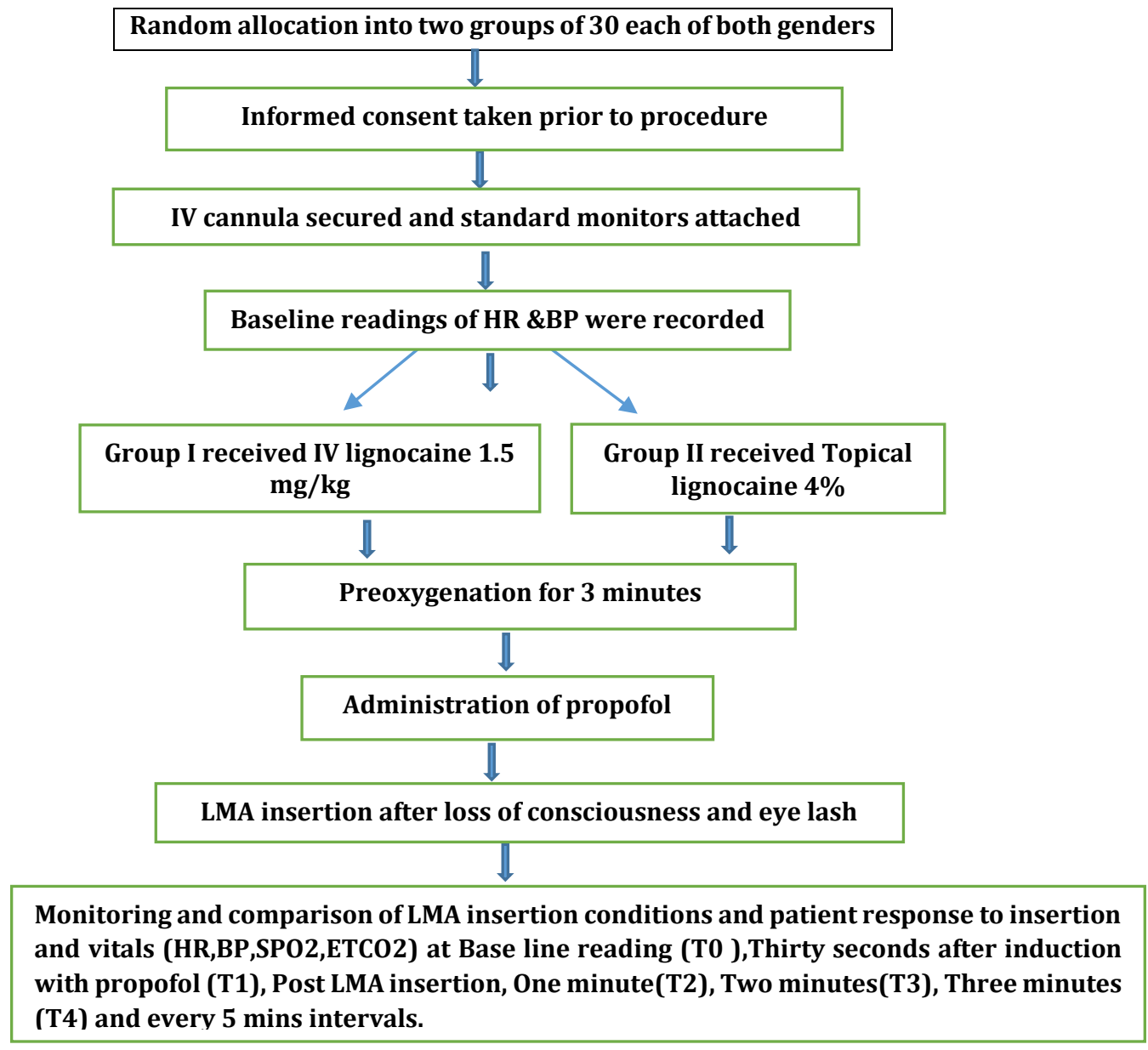

Flowchart Showing Preop and Intraop Management

The LMA was inserted 60 seconds after completion of propofol injection after loss of consciousness and eye lash reflex. In case, eye lash reflex was still intact further boluses of $0.5 \mathrm{mg} / \mathrm{kg}$ propofol iv were used. Classic LMA size 4 was used for males and size 3 for females. All LMA insertions were done using the method described by Dr. Archie Brain. Water based jelly was applied on the posterior surface of the LMA and pressed along the hard plate using the index finger. It was finally pushed further down till resistance was felt. Cuff was inflated with prescribed air in according to LMA size. Proper LMA placement was confirmed

For insertion of LMA: Excellent conditions include gagging of grade 0 / 1 with no laryngospasm and coughing. Good conditions include gagging with grade $0 / 2$ with no laryngospasm and coughing. Poor conditions are grade 2 gagging with coughing and no laryngospasm. Unacceptable conditions include grade 3 gagging with coughing and laryngospasm. In Group I, IV lignocaine $1.5 \mathrm{mg} / \mathrm{kg}$ was administered over 30 seconds following preoxygenation with 100 percent oxygen for 3 minutes, followed by inj. Propofol 2 mg / kg. Using the standard form, LMA insertion was attempted. In Group II, lignocaine aerosol was applied to the posterior pharyngeal wall and its two sides (total of 4 sprays, $\mathrm{mg}$ ) after preoxygenation with 100 percent oxygen for 3 minutes, accompanied by inj. Propofol $2 \mathrm{mg} / \mathrm{kg}$ and LMA insertion were reported after 30 seconds of propofol, as well as LMA insertion conditions and vital parameters.

\section{Grades of Gagging 12}

- $\quad$ Grade 0 - No Gagging

- $\quad$ Grade 1 - Gagging settled within 30 seconds

- Grade 2 - a further dose of induction agent needed

- $\quad$ Grade 3 - Suxamethonium required

- $\quad$ ECG, NIBP, SPO2 and ETCO2 were reported at baseline, 30 seconds after induction, post LMA insertion, one minute, two minute, three minutes.

The lungs of the patient were not manually ventilated and no volatile agents or nitrous oxide were administered until the first set of readings was taken after insertion of the LMA. Nitrous oxide (66\% in 02) and vecuronium at a dose of $0.1 \mathrm{mg}$ / $\mathrm{kg}$ were initiated during the second and third minute recording of patients after proper LMA confirmation.

Further anaesthesia was maintained with standard protocol for general anaesthesia as per surgery. Continuous monitoring of ECG, HR, BP, SPO2, ETCO2 was done at every 5 minute intervals.

\section{Statistical Analysis}

Statistical analysis was performed using paired $t$ - test and categorical data analysed using chi - square test. A P - value of $<0.05$ was accepted as statistically significant. 


\section{Sample size}

Confidence interval (2 - sided): $95 \%$

Power: $80 \%$

Ratio of sample size: 1

\section{RESULTS}

\begin{tabular}{|c|c|c|}
\hline Gender & Group I & Group II \\
\hline Male & $21(70 \%)$ & $22(73 \%)$ \\
\hline Female & $09(30 \%)$ & $08(27 \%)$ \\
\hline Type of surgery & Group I & Group II \\
\hline Cholecystectomy & $2(6.66 \%)$ & $1(3.33 \%)$ \\
\hline Skin grafting & $4(13.3 \%)$ & $9(30 \%)$ \\
\hline Tension band wiring & $5(16.6 \%)$ & $4(13.3 \%)$ \\
\hline $\begin{array}{l}\text { Modified radical } \\
\text { mastectomy }\end{array}$ & $6(20 \%)$ & $2(6.66 \%)$ \\
\hline Herniorrhaphy & $3(10 \%)$ & $3(10 \%)$ \\
\hline Humerus plating & $2(6.66 \%)$ & $4(13.3 \%)$ \\
\hline Fistulectomy & $1(3.33 \%)$ & $2(6.66 \%)$ \\
\hline Ulnar plating & $3(10 \%)$ & $2(6.66 \%)$ \\
\hline D.H.S & $1(3.33 \%)$ & $1(3.33 \%)$ \\
\hline Amputation & $3(10 \%)$ & $2(6.66 \%)$ \\
\hline Total & $30(100 \%)$ & $30(100 \%)$ \\
\hline Conditions of LMA insertion & Group I & Group II \\
\hline Excellent & $20(66.6 \%)$ & $25(83.3 \%)$ \\
\hline Good & $4(13.3 \%)$ & $3(10 \%)$ \\
\hline Poor & $4(13.3 \%)$ & $1(3.33 \%)$ \\
\hline Unacceptable & $2(6.66 \%)$ & $1(3.33 \%)$ \\
\hline Airway Characteristics & Group I & Group II \\
\hline \multicolumn{3}{|l|}{ Gagging } \\
\hline Absent & $22(73.3 \%)$ & $27(90 \%)$ \\
\hline$<30$ sce & $2(6.66 \%)$ & $1(3.33 \%)$ \\
\hline Propofol required & $5(16.6 \%)$ & $2(6.6 \%)$ \\
\hline Succinyl choline required & $1(3.33 \%)$ & $0(0 \%)$ \\
\hline \multicolumn{3}{|l|}{ Coughing } \\
\hline Absent & $27(90 \%)$ & $29(96.6 \%)$ \\
\hline Present & $3(10 \%)$ & $1(3.33 \%)$ \\
\hline \multicolumn{3}{|l|}{ Laryngospasm } \\
\hline Absent & 28 (93.33\%) & $29(96.6 \%)$ \\
\hline Present & $2(6.6 \%)$ & $1(3.33 \%)$ \\
\hline \multicolumn{3}{|l|}{ No. of attempts } \\
\hline One & $25(83.3 \%)$ & $29(96.6 \%)$ \\
\hline Two & $4(13.3 \%)$ & $1(3.33 \%)$ \\
\hline More & $1(3.33 \%)$ & $0(0 \%)$ \\
\hline
\end{tabular}

Both groups were comparable and no statistical difference was found among these groups with respect to age, sex, ASA status and type of surgeries.

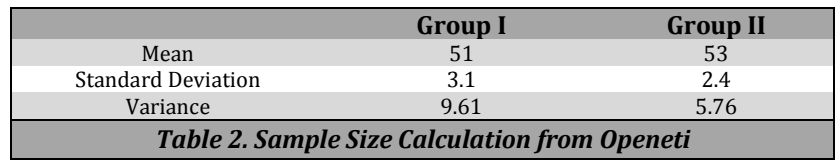

\begin{tabular}{|c|c|c|c|c|c|c|c|c|}
\hline \multirow[b]{2}{*}{ Time } & \multicolumn{4}{|c|}{ Group I } & \multicolumn{4}{|c|}{ Group II } \\
\hline & $\begin{array}{c}\text { Mean } \\
\text { Heart } \\
\text { Rate }\end{array}$ & $\begin{array}{c}\text { Mean } \\
\text { SBP }\end{array}$ & $\begin{array}{c}\text { Mean } \\
\text { DBP }\end{array}$ & MAP & $\begin{array}{c}\text { Mean } \\
\text { Heart } \\
\text { Rate }\end{array}$ & $\begin{array}{c}\text { Mean } \\
\text { SBP }\end{array}$ & $\begin{array}{l}\text { Mean } \\
\text { DBP }\end{array}$ & MAP \\
\hline $\begin{array}{c}\text { Pre-operative } \\
\text { T0 }\end{array}$ & 87 & 129 & 81 & 97 & 85 & 129 & 77 & 95 \\
\hline $\begin{array}{c}\text { Post Induction } \\
\text { T1 }\end{array}$ & 93 & 119 & 73 & 88 & 92 & 120 & 72 & 88 \\
\hline $1 \mathrm{~min} \mathrm{~T} 2$ & 95 & 129 & 80 & 96 & 91 & 126 & 78 & 93 \\
\hline $2 \mathrm{~min} \mathrm{~T} 3$ & 89 & 129 & 79 & 95 & 87 & 126 & 77 & 93 \\
\hline $3 \mathrm{~min} \mathrm{~T} 4$ & 87 & 128 & 79 & 95 & 86 & 126 & 76 & 93 \\
\hline \multicolumn{9}{|c|}{ Table 3. Mean Heart Rate, Mean SBP, DBP, MAP } \\
\hline
\end{tabular}

Table 3 shows significant rise in mean heart rate post induction in both groups. At two and three minutes post LMA insertion heart rate remained slightly high from baseline but was not significant. Post induction significant fall in SBP, DBP, and MAP was seen in both the groups. Changes in blood pressure at 2 and 3 minutes were slightly lower but not significant.

\section{DISCUSSION}

To avoid gagging, coughing and laryngospasm, the LMA insertion requires the suppression of upper airway reflexes. Various IV induction agents were used For LMA insertion. ${ }^{4-6}$ For the injection of an LMA, thiopentone has been tried but produces conditions less satisfactory than propofol.13,14 Propofol is known to effectively suppress both pharyngeal and laryngeal reflexes than thiopentone. However, studies indicate a 38 - 60 percent occurrence of inadequate insertion with normal induction doses of propofol $(2-3 \mathrm{mg} / \mathrm{kg}$ ) associated with side effects such as swallowing, gagging, coughing, limb movement and haemodynamic instability if an excess dose of propofol is used.

It has been shown that lignocaine suppresses cough and is reliant on the dosage. When used topically or intravenously, lignocaine often decreases the cardiovascular response to tracheal intubation and LMA insertion.7,8 The hemodynamic responses to LMA insertion are negligible which rarely requires intervention. Topical lignocaine has a therapeutic effect for 20 - 40 minutes and by the time of recovery its local anaesthetic activity would be abolished. ${ }^{9}$

\section{Conditions for LMA Insertion}

In the report, we found that when topical lignocaine was sprayed onto the posterior pharyngeal wall (Group II) with less occurrence of gagging and coughing, LMA insertion conditions were better. It gave us the ability to protect the patient's airway with LMA quickly and efficiently, resulting in excellent / acceptable LMA insertion conditions.

The result was consistent with that stated by Cook and Seavell et al. in their study comparing topical and intravenous lignocaine with thiopentone for LMA Insertion. ${ }^{10}$ Number of attempts to pass the LMA in Group II compared to Group I, was also significantly less. This was possibly due to airway reflex suppression by the topical lignocaine applied to the pharyngeal posterior wall. In Group I, laryngospasm occurred in 2 patients.

\section{Comparison of Heart Rate Changes}

In both cases, the baseline heart rate was comparable. The mean heart rate increased significantly $(\mathrm{P}<0.05)$ in both groups, post induction (T0 - T1: $6.1+7.58$ of GroupI, Category $\mathrm{I},-6.35+5.3)$. This rise was similar in both groups $(\mathrm{P}>0.05)$. Post insertion of LMA in $1 \mathrm{~min}$. Further rise in heart rate (T0 T2: $7.85=5.91$ in group I, $5.75=5.99$ in Group II), which was a relative rise in Group II, but not significant.

In both groups at two and three minutes. The heart rate decreased after LMA insertion and achieved a level equal to the baseline. LMA insertion triggers the pressor response which increases HR, SBP and DBP.

\section{Comparison of Systolic Blood Pressure}

In both classes, there was a reduction in SBP after induction. In individual classes, it was significant $(\mathrm{P}<0.05)$ but changes were not significant when compared to both classes. The SBP increased post insertion of LMA in both, however it was not important relative to the baseline. 
The changes in SBP were not significant, at 2 and 3 minutes after LMA insertion. Wilson et al. noted that insertion of LMA induced a temporary rise in SBP. ${ }^{10}$ Cook and Seveall et al. observed that there was no substantial difference in SBP (IV lignocaine VS topical) post LMA insertion lignocaine. Our results were consistent with the results of the Cook and Seveall's observations. The pressor response was found to decrease stimulation by LMA with propofol by the use of lignocaine.

\section{Comparison of Diastolic Blood Pressure}

There was a substantial decrease in the DBP after induction, (P $<0.05$ ) of the individual groups (T0 - T1: $8.5+5.36$ of the individual groups) Group I, Group II, $6.10+4.80$, which was comparable in both groups. DBP increased after LMA insertion, but it was non-significant relative to the baseline. Such results were compatible with previous researches carried out by different Scientists.

\section{Comparison of Mean Arterial Pressure}

The MAP decreased to a substantial level after induction. In both groups (T0 - T1:9.34+ in group I, 7.3+3.6 in group II), Groups that were comparable $(\mathrm{P}>0.05)$. When contrasted, this was extremely important if intragroup was considered $(\mathrm{P}<$ 0.001). There after LMA, MAP was increased in both groups, one-minute after insertion of LMA but that was not important. $(\mathrm{P}>0.05)$ ( T0 - T2: in group I $1=5.5$, in group II $1.7=8.2$ ). Similarly, at 2 and 3 minutes, the average deviation from the mean from the baseline was not relevant either in the intra group or in $(\mathrm{P}>0.05)$ between the two classes. These results are similar to forest and wood, and accounted for attenuated pressor response to LMA and lignocaine. ${ }^{11}$

\section{CONCLUSIONS}

In conclusion, the current research shows that topical 10 percent of aerosol lignocaine when sprayed onto the back of the pharyngeal wall 3 minutes prior to propofol induction, does not provide excellent conditions for LMA insertion, without administering the neuromuscular blockers. It was observed that in group of topical lignocaine no of attempts for LMA insertion was significantly less. Even after the LMA was introduced, changes were insignificant In HR, SBP, DBP and MAP.

We therefore conclude that greater insertion conditions are provided by topical lignocaine. But with IV lignocaine hemodynamics' stability is the same as topical lignocaine.

Data sharing statement provided by the authors is available with the full text of this article at jemds.com.
Financial or other competing interests: None.

Disclosure forms provided by the authors are available with the full text of this article at jemds.com.

\section{REFERENCES}

[1] Almeida G, Costa AC, Machado HS. Supraglottic airway devices: a review in a new era of airway management. J Anesth Clin Res 2016;7:647.

[2] Verghese C, Mena G, Ferson DZ, et al. Laryngeal mask airway. In: Hagberg CA, ed. Benumof's and Hagberg's Airway Management. 3rd edn. Philadelphia: Elsevier Saunders 2013:443-65.

[3] Brimacombe J, Berry A. Insertion of LMA-an indication for propofol ? Anaesth Intensive Care 1992;20(3):394-5.

[4] Driver IK, Wiltshire S, Mills P, et al. Midazolam coinduction and laryngeal mask insertion. Anaesthesia 1996;51(8):782-4.

[5] Stoneham MD, Bree SE, Sneyd JR. Facilitation of laryngeal mask insertion. Effects of lignocaine given intravenously before induction with propofol. Anaesthesia 1995;50(5):464-6.

[6] Goyagi T, Tanaka M, Nishikawa T. Fentanyl decreases propofol requirement for laryngeal mask airway insertion. Acta Anaesthesiol Scand 2003;47(6):771-4.

[7] Denlinger JK, Ellison N, Ominsky AJ. Effects of intratracheal lidocaine on circulatory responses to tracheal intubation. Anesthesiology 1974;41(4):409-12.

[8] Abou-Madi MN, Keszler H, Yacoub JM. Cardiovascular reactions to laryngoscopy and tracheal intubation following small and large doses of lidocaine. Can Anaesth Soc J 1977;24(1):12-9.

[9] Kirkpatrick MB. Lidocaine topical anesthesia for flexible bronchoscopy. Chest 1989;96(5):965-6.

[10] Seavell CR, Cook TM, Cox CM. Topical lignocaine and thiopentone for the insertion of a laryngeal mask airway. Anaesthesia 1996;51(7):699-701.

[11] Wood ML, Forrest ET. The haemodynamic response to the insertion of the laryngeal mask airway: a comparison with laryngoscopy and tracheal intubation. Acta Anaesthesiol Scand 1994;38(5):510-3.

[12] Ahmed S, Jain N, Saksena S. Comparative evaluation of topical and intravenous lignocaine for insertion of laryngeal mask airway with propofol. Int J Adv Med 2018;5(3):573-7.

[13] Scanlon P, Carey M, Power M, et al. Patient response to laryngeal mask insertion after induction of anaesthesia with propofol or thiopentone. Can J Anaesth 1993;40(9):816-8.

[14] Brown GW, Patel N, Ellis FR. Comparison of propofol and thiopentone for laryngeal mask insertion. Anarsthesia 1991;46(9):771-2. 